\title{
ATITUDES RELATIVAMENTE À HOMOPARENTALIDADE DE FUTUROS/AS INTERVENIENTES DA REDE SOCIAL
}

\author{
Jorge Gato ${ }^{2}$ \\ Daniela Freitas ${ }^{2}$ \\ Anne Marie Fontaine ${ }^{2}$
}

Resumo: Neste estudo procurámos caracterizar as atitudes relativamente à homoparentalidade feminina e masculina, por parte de um conjunto de futuros/as intervenientes da rede social. Cada participante $(N=1288)$ leu uma de 14 vinhetas contendo a descrição de uma situação de adoção, na qual a orientação sexual e o estatuto conjugal dos/as candidatos/as a adotantes foram manipulados experimentalmente. Posteriormente, os/as participantes pronunciaram-se sobre diversos aspetos da competência parental dos/as candidatos/as. Apesar de as competências parentais dos/as candidatos/as terem sido avaliadas positivamente, a parentalidade heterossexual foi avaliada de forma mais positiva do que a homoparentalidade. Além disso, os/as participantes consideraram que as lésbicas ou os gays celibatários receberiam mais apoio da comunidade do que os casais do mesmo sexo (femininos ou masculinos). No caso das lésbicas, verificou-se ainda uma maior probabilidade de atribuição da custódia da criança a uma pessoa solteira do que a um casal. Esta visão heteronormativa da parentalidade é discutida e são consideradas implicações para a formação académica dos/as futuros/as intervenientes da rede social, nomeadamente no que diz respeito à necessária inclusão desta temática nos curricula universitários.

Palavras-Chave: homoparentalidade, competência parental, atitudes

Atitudes toward Same-Sex Parenting of Future Professionals in Social Intervention (Abstract): In this study, we sought to characterize the attitudes of future

\footnotetext{
${ }^{1}$ Este trabalho foi financiado por uma bolsa de doutoramento atribuída ao primeiro autor pela Fundação para a Ciência e Tecnologia (SFRH/BD/41752/2007). A correspondência relativa a este artigo deve ser endereçada a Jorge Gato, Faculdade de Psicologia e de Ciências da Educação da Universidade do Porto, Rua Alfredo Allen 4200-135, Porto, Portugal, Tlf.: 226079 700, ext. 380, Fax: 226079 725, E-mail: jorgegato@fpce.up.pt

2 Centro de Psicologia Diferencial, Faculdade de Psicologia e de Ciências da Educação, Universidade do Porto
} 
professionals of the social network towards lesbian and gay parenting. Each participant $(N=1288)$ read one of 14 vignettes describing an adoption situation. The vignettes were identical except for the sexual orientation and the relational status of the candidates. After reading the vignette, participants rated various aspects of the parental competence of the candidates. Results showed that although all candidates were rated positively, heterosexual parents were favored over homosexual parents. Additionally, participants considered that single lesbian or gay candidates would receive more social support from the community than same-sex couples. In the case of lesbian parents, custody was also awarded with greater probability to a single woman than to a couple. This heteronormative view of parenting is discussed and implications are drawn in terms of the students' academic training, namely the necessary inclusion of this issue in the curricula of university degrees.

Key-Words: lesbian and gay parenting, parental competences, attitudes

\section{Atitudes Relativamente à Homoparentalidade de Futuros/as Intervenientes da Rede Social}

Muitas lésbicas e gays são mães e pais ou exercem funções parentais, pelo que, desde os anos 1970, esta configuração familiar tem sido objeto de investigação psicológica. Sendo esta ainda uma temática pouco estudada em Portugal (enquanto exceções, em termos de publicações, ver os trabalhos de Almeida, 2009; Ferreira 2006; Leal, 2004; Moz, 2006), propomo-nos neste trabalho analisar as atitudes relativamente a estas famílias.

Apesar de existirem também mães e pais que se identificam como bissexuais, transgénero ou queer, a investigação tem-se focado, principalmente, nas famílias encabeçadas por lésbicas e gays, casados/as ou celibatários/as. Numa primeira fase, os estudos pretenderam dar resposta às objeções levantadas por tribunais ingleses e americanos, relativamente à custódia legal de crianças cujas mães adotaram uma identidade lésbica. Patterson (2002) sistematizou os argumentos contra a homoparentalidade da seguinte forma: i) por estas famílias não disporem de uma figura materna e paterna, rapazes e raparigas não se iriam desenvolver de forma harmoniosa e saudável, apresentando dificuldades em termos do seu desenvolvimento psicológico; ii) o facto de se ser educado por gays ou lésbicas poderia comprometer o desenvolvimento da identidade sexual e de género das crianças, propiciando a homossexualidade; iii) as crianças seriam vítimas de discriminação, dada a homofobia que ainda caracteriza a sociedade; e iv) as crianças correriam maior risco de ser vítimas de abuso sexual, particularmente por parte dos progenitores do sexo masculino. 
De forma a responder às objeções referidas, a investigação tem incidido, quer na análise das práticas parentais de lésbicas e gays, quer no desenvolvimento psicossocial de crianças educadas em contexto homoparental (para revisões destes estudos ver, por exemplo, Biblarz \& Stacey, 2010; Patterson, 2002; Tasker, 2005; Vecho \& Schneider, 2005; para uma revisão, em língua portuguesa, ver Gato \& Fontaine, 2011a). Apesar de terem sido objeto de algumas críticas, nomeadamente, a utilização da heteroparentalidade como referência normativa, ${ }^{3}$ estas investigações permitiram acumular um corpo de resultados consistente, concluindo, de uma forma genérica, que as competências parentais não diferem em função da orientação sexual das pessoas e que as crianças educadas por lésbicas e gays apresentam um desenvolvimento psicossocial semelhante ao dos filhos de pais heterossexuais.

Como salientou Alarcão (2000, p. 230), "o maior risco para estas famílias está na atitude segregadora da sociedade heterossexual”. Assim, um outro conjunto de estudos tem destacado a influência do contexto social no qual as famílias homoparentais estão inseridas e sublinhado o papel negativo da estigmatização social, geradora de stresse familiar (Vecho \& Schneider, 2005). Em Portugal, as atitudes negativas relativamente à homoparentalidade estão particularmente patentes na proibição da adoção por casais do mesmo sexo (Lei da adoção n. ${ }^{\circ}$ 31, Diário da República, 2003; Lei das uniões de facto n. ${ }^{\circ}$ 7, Diário da República, 2001; Lei do casamento n. ${ }^{\circ}$ 9, Diário da República, 2010) e percetíveis, em termos sociais, no facto de apenas $19 \%$ de uma amostra representativa da população portuguesa concordar com a mesma (Comissão Europeia, 2007).

O preconceito poderá ainda constituir-se como um fator de stresse adicional se for manifestado no relacionamento com as pessoas cujo papel é o de prestar assistência às necessidades educacionais, de saúde e sociais das famílias. Por exemplo, Bos, van Balen, van den Boom e Sandfort (2004) constataram que mães lésbicas com mais experiências de rejeição institucional apresentavam níveis mais elevados de stresse parental. Em Portugal, uma análise do discurso de técnicos/as de saúde mental evidenciou uma visão da homossexualidade como uma orientação "não natural", resultado de um défice ou uma falha desenvolvimental (Moita, 2006). O mesmo estudo permitiu ainda constatar uma tendência das pessoas ouvidas para avaliar os/as clientes não heterossexuais como mais individualistas, agressivos/as ou com mais dificuldades de relacionamento do que os/as clientes heterossexuais, e

\footnotetext{
${ }^{3} \mathrm{Na}$ opinião de alguns autores (e.g., Clarke, 2000), esta comparação reforça a heteronormatividade vigente e dificulta uma compreensão aprofundada das dinâmicas próprias da homoparentalidade. Para uma análise desta questão, consultar Gato e Fontaine (2011b).
} 
para ignorar dimensões mais positivas ou contextuais que poderiam estar associadas às orientações não heterossexuais.

Como referiu Patterson (2002), as atitudes negativas relativamente à homoparentalidade estão provavelmente associadas à convicção de que a presença de dois progenitores de sexo diferente é indispensável para o bom exercício da parentalidade e para o desenvolvimento saudável da criança. Esta convicção não deixa, no entanto, de ser contraditória com o facto de pessoas solteiras poderem ser candidatas a adotantes em Portugal, independentemente da sua orientação sexual. Assim, torna-se também relevante investigar em que medida as atitudes relativamente à homoparentalidade variam em função do estatuto conjugal dos/as progenitores/as.

Pretendemos assim neste trabalho responder às seguintes perguntas: como é que um conjunto de futuros/as profissionais da rede social avalia a competência parental de candidatos/as a adotantes, em função da orientação sexual desses/as candidatos/as? Adicionalmente, em que medida é que as avaliações da competência parental dos/as candidatos/as são influenciadas pelo seu estatuto conjugal?

Antes de respondermos a estas questões, apresentamos uma breve revisão dos estudos no domínio que pretendemos investigar, isto é, as atitudes perante a parentalidade em função da orientação sexual e estatuto conjugal dos/as progenitores/as.

\section{Atitudes relativamente à homoparentalidade}

As investigações que abordaram as atitudes relativamente à homoparentalidade não são numerosas (Vecho \& Schneider, 2005). Muitas destas investigações recorreram a uma metodologia semiexperimental, na qual são utilizadas vinhetas que retratam uma candidatura a adoção, um processo judicial de atribuição de custódia ou a descrição de uma cena familiar, com manipulação da orientação sexual dos/as progenitores/as. Posteriormente, os/as participantes são questionados sobre a competência das figuras parentais em questão ou sobre aspetos do desenvolvimento da criança. Desta forma, é possível comparar-se as respostas que dizem respeito a situações de parentalidade normativa com as respostas que se referem a núcleos homoparentais. Frequentemente, estes resultados são também relacionados com outras características dos/as respondentes (e.g., sexo, grau de preconceito relativamente a lésbicas e gays, nível de religiosidade). Uma síntese dos estudos sobre as atitudes relativamente à homoparentalidade pode ser encontrada no Quadro 1. 


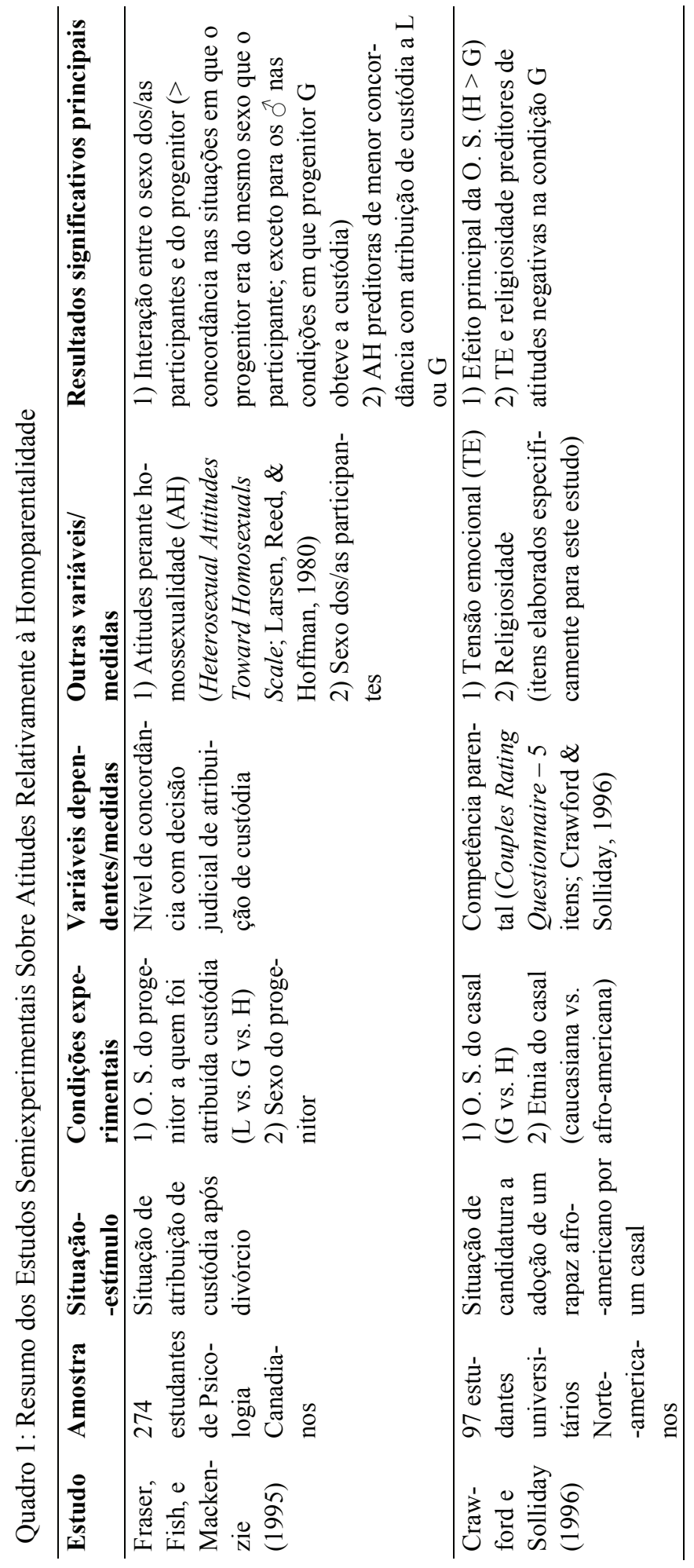




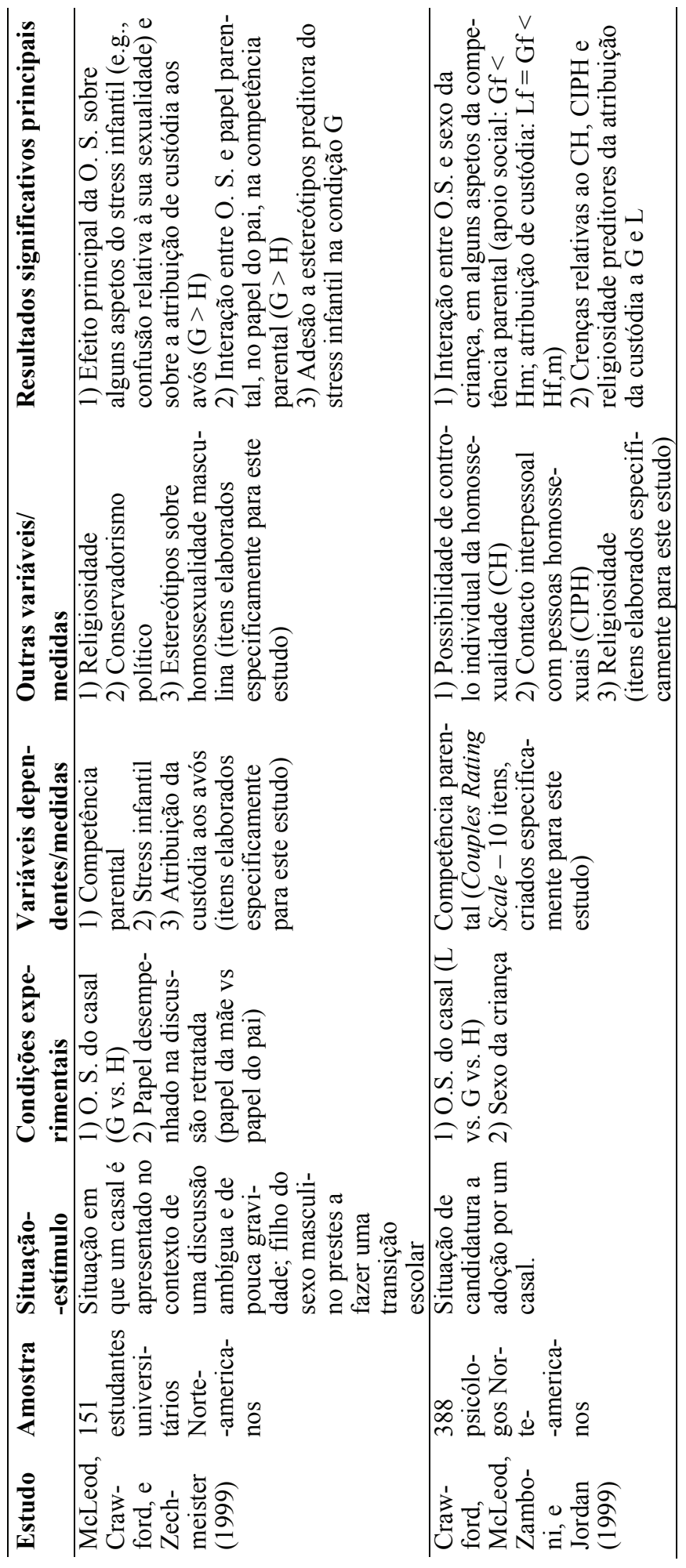




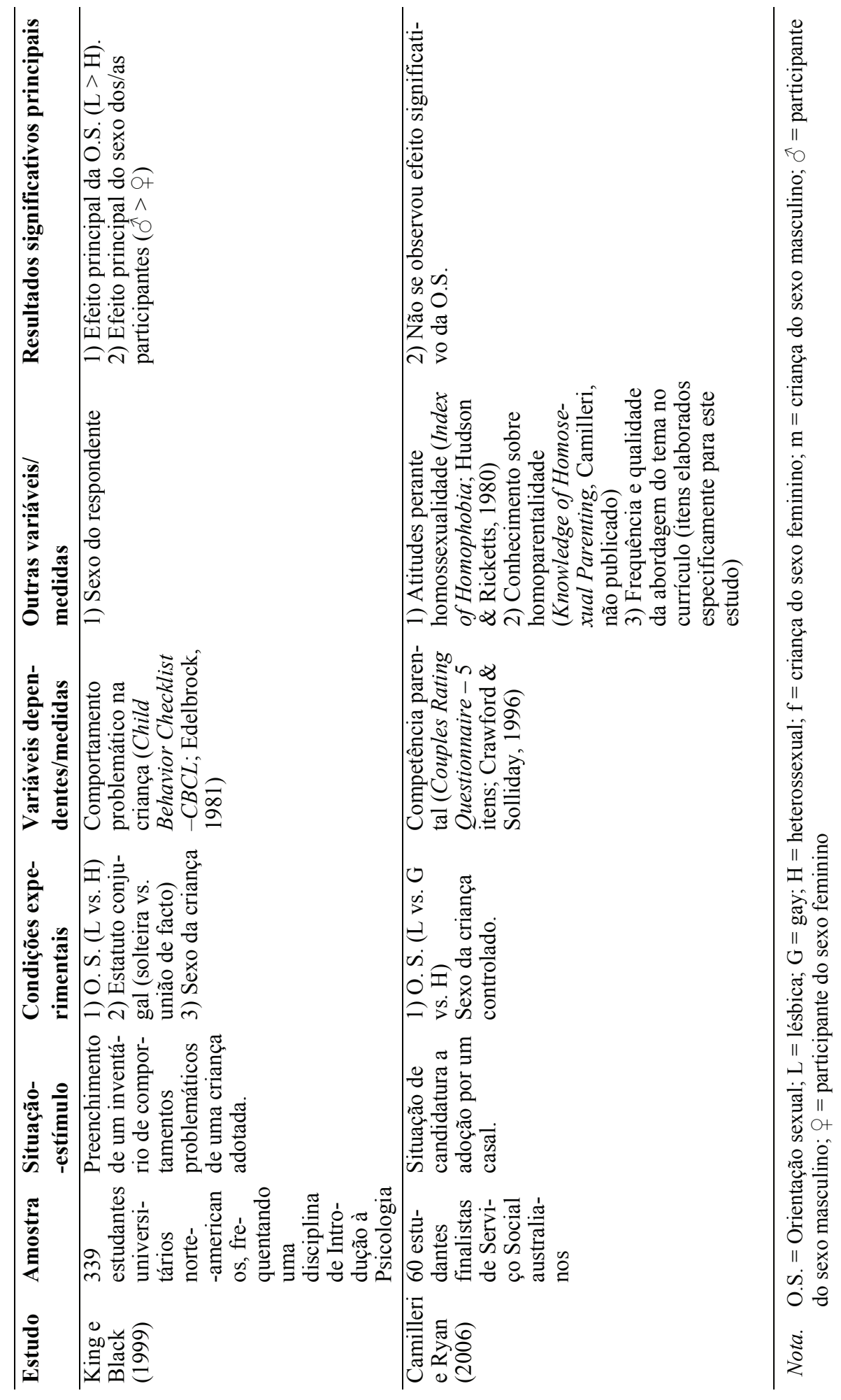


Como se pode constatar através da análise do Quadro 1, os estudos são, na sua totalidade, provenientes de países anglo-saxónicos e, com a exceção de Crawford, McLeod, Zamboni e Jordan (1999), foram realizados junto de amostras de estudantes. Globalmente, evidenciam uma perspetiva heteronormativa da parentalidade, isto é, embora a homoparentalidade não seja derrogada, as situações de parentalidade heterossexual são geralmente favorecidas, quer no que diz respeito à competência do sistema parental, quer no que se refere ao desenvolvimento da criança. As investigações recenseadas não identificaram diferenças entre as atitudes perante famílias homoparentais femininas e masculinas (Camilleri \& Ryan, 2006; Crawford et al., 1999; Fraser, Fish, \& Mackenzie, 1995). É também visível uma associação entre atitudes mais negativas relativamente à homoparentalidade e (i) atitudes negativas relativamente às pessoas homossexuais (Fraser et al., 1995); (ii) adesão a representações estereotipadas da homossexualidade masculina (McLeod, Crawford, \& Zechmeister, 1999); (iii) nível mais elevado de religiosidade (Crawford \& Solliday, 1996; Crawford et al., 1999); (iv) crença no facto de a homossexualidade ser uma opção (Crawford et al., 1999); e (v) pertença do participante ao sexo masculino (King \& Black, 1999).

Apenas uma das investigações recenseadas (King \& Black, 1999) considerou o papel desempenhado pelo estatuto conjugal dos progenitores nas atitudes relativamente à homoparentalidade. Os autores verificaram que uma situação de conjugalidade lésbica não era considerada mais nociva para o desenvolvimento da criança, do que uma situação de celibato. Um estudo paralelo comparando casais de gays e gays celibatários não foi ainda realizado. No entanto, como se verá de seguida, o estatuto conjugal dos progenitores é uma variável que poderá interagir de forma significativa com a sua orientação sexual, particularmente no contexto português.

\section{Atitudes relativamente à monoparentalidade}

Não obstante a maior frequência e consequente normalização do fenómeno, a monoparentalidade continua a ser olhada com alguma apreensão. Subjacente a esta situação está a perceção da elevada carga financeira associada à educação de uma criança ou a valorização da família nuclear tradicional (Usdanksy, 2009). Efetivamente, nos EUA, onde a ideologia do casamento e da família parecem particularmente salientes, as pessoas solteiras encontram maiores barreiras na candidatura a processos de adoção ou de procriação medicamente assistida (Millbank, 1997, in DePaulo \& Morris, 2005) e parecem sujeitas a maior discriminação (DePaulo \& Morris, 2005; Morris, Sinclair, \& DePaulo, 2007). Nesta medida, alguns estudos constata- 
ram que as pessoas solteiras eram descritas predominantemente como solitárias, infelizes, inseguras e teimosas, sendo também consideradas menos responsáveis, maduras ou bem-ajustadas, do que as suas congéneres casadas (e.g., Etaught \& Birdoes, 1991, in Morris et al., 2007). No que diz respeito à adoção singular, dois tipos de estigma parecem estar presentes. Por um lado, o estigma já associado à adoção no geral, frequentemente vista como uma via de recurso para a formação de uma família, devido à putativa incapacidade dos/as candidatos/as gerarem um filho biológico (Pavao, 1998, in Boyer, 2005). Por outro lado, o facto de se poder considerar que o/a candidato/a solteiro/a não cumpriu tarefas sociais altamente valorizadas, tais como casar e ter filhos (Morris et al., 2007; Pakizegi, 2007). Se, tal como os estudos citados sugerem, as pessoas solteiras forem menos socialmente aceites do que as pessoas casadas, a sua competência parental também poderá ser mais posta em causa. No entanto, não se sabe se este raciocínio é universal ou se se aplica apenas às pessoas heterossexuais. Como já referimos, em Portugal a monoparentalidade não constitui um impedimento legal para candidatura a adoção, mas sim a biparentalidade lésbica ou gay. Assim, à apreensão patente na sociedade e lei portuguesas acerca da adoção por casais do mesmo sexo, pode acrescer ou não uma avaliação menos positiva do estatuto conjugal celibatário.

O objetivo principal do estudo empírico que apresentamos em seguida é o de responder à seguinte questão: como varia a avaliação da competência parental de candidatos/as a adotantes, em função da sua orientação sexual e do seu estatuto conjugal? Para operacionalizar este propósito, utilizou-se uma metodologia semiexperimental semelhante à utilizada noutros estudos (ver Quadro 1), nos quais os/as participantes se pronunciaram sobre uma situação de candidatura a adoção, respondendo posteriormente a um conjunto de itens relativos à perceção que têm das competências parentais dos/as candidatos/as a adotantes.

\section{Método}

\section{Participantes}

A amostra, de tipo não probabilístico, é constituída por um conjunto de pessoas, que, pelas circunstâncias associadas à sua futura profissão, terão probabilidade de estabelecer relacionamentos profissionais com as famílias homoparentais. Foram selecionados indivíduos que estão prestes a iniciar a sua prática profissional, isto é, a frequentar os últimos anos $\left(3^{\circ}, 4^{\circ}, 5^{\circ}\right.$ ou $\left.6^{\circ}\right)$ das respetivas licenciaturas. Assim, participaram neste estudo 1288 estudantes, provenientes de 12 instituições de ensino superior de diversas regiões do país, frequentando nove cursos, distribuídos por quatro áreas curriculares: (i) 
psicossocial (Psicologia, Sociologia, Serviço Social e Educação Social), (ii) saúde (Medicina e Enfermagem), (iii) educação (Ensino Básico e Educação de Infância) e (iv) jurídica (Direito), com uma idade compreendida entre os 21 e os 56 anos $(M=23.10 ; D P=4.25)$. A caracterização pormenorizada da amostra pode ser consultada na Tabela 1 .

Tabela 1: Características Sociodemográficas da Amostra

\begin{tabular}{lll}
\hline & $N$ & Percentagem \\
\hline Sexo & 1095 & 85.0 \\
Feminino & 193 & 15.0 \\
$\quad$ Masculino & & \\
Curso & 320 & 24.8 \\
$\quad$ Psicologia & 88 & 6.8 \\
$\quad$ Serviço Social & 47 & 3.6 \\
$\quad$ Educação Social & 164 & 12.7 \\
$\quad$ Medicina & 261 & 20.3 \\
$\quad$ Enfermagem & 60 & 4.7 \\
$\quad$ Ensino Básico & 127 & 9.9 \\
$\quad$ Educação de Infância & 84 & 6.5 \\
$\quad$ Sociologia & 137 & 10.6 \\
$\quad$ Direito & & \\
Estado Civil & 1209 & 94.1 \\
$\quad$ Solteiro & 69 & 5.4 \\
Casado / União de facto & 5 & 0.4 \\
$\quad$ Divorciado / Separado & 2 & 0.2 \\
Viúvo & & \\
Nível de Educação Parental ${ }^{1}$ & 620 & 48.9 \\
$\quad$ Ensino Básico & 369 & 29.1 \\
Ensino Secundário & 278 & 21.9 \\
Ensino Superior & & \\
Contacto com informação científica sobre Homossexuali- & & \\
dade/ Homoparentalidade & 691 & 53.9 \\
$\quad$ Não & & \\
Sim & 492 & 38.2 \\
$\quad$ Em Disciplina & 56 & 4.3 \\
$\quad$ Em Conferência & 34 & 2.6 \\
$\quad$ Outro local & &
\end{tabular}




\section{Contacto interpessoal com lésbicas e gays}

$\begin{array}{lll}\text { Ausência de contacto ou desconhecimento do mesmo } & 684 & 53.8\end{array}$

$\begin{array}{lll}\text { Presença de contacto } & 578 & 45.4\end{array}$

\section{Importância atribuída aos Valores Religiosos ${ }^{2}$}

Nada ou pouco importantes $\quad 490$

Algo importantes

Muito importantes

Nota: ${ }^{1}$ O nível de educação parental corresponde ao nível de formação mais elevado obtido por um dos progenitores; ${ }^{2}$ Os valores religiosos foram avaliados através de uma escala tipo Likert de 1 (nada importantes) a 6 (extremamente importantes); valores nada ou pouco importantes referem-se aos/às participantes que responderam aos dois primeiros pontos da escala; algo importantes, aos dois pontos intermédios; e muito importantes, aos últimos dois pontos.

\section{Desenho}

Recorreu-se a um desenho semiexperimental interparticipantes, em que a orientação sexual e o estatuto conjugal dos/as candidatos/as a adotantes, retratados numa vinheta, foram manipulados. Assim, cada participante foi confrontado/a com uma única descrição de uma situação de adoção. Deste modo, as situações apresentadas variam segundo um desenho fatorial, cruzando a orientação sexual do/s e da/s adotante/s (Lésbica vs. Gay vs. Heterossexual), o seu estatuto conjugal (Casado vs. Solteiro) e o sexo da criança (Rapariga vs. Rapaz), obtendo-se, na totalidade 14 situações diferentes. ${ }^{4} \mathrm{O}$ efeito do sexo da criança foi controlado equilibrando os grupos. Após a leitura da descrição, os/as participantes foram solicitados/as a antecipar alguns aspetos da competência parental dos/as candidatos/as.

${ }^{4}$ Catorze vinhetas foram distribuídas aleatoriamente pelos/as participantes: (a) um casal heterossexual que pretende adotar uma rapariga $(n=98)$; (b) um casal heterossexual que pretende adotar um rapaz ( $n=92)$; (c) um casal de gays que pretende adotar uma rapariga $(n=89)$; (d) um casal de gays que pretende adotar um rapaz $(n=95)$; (e) um casal de lésbicas que pretende adotar uma rapariga $(n=96)$; (f) um casal de lésbicas que pretende adotar um rapaz $(n=94)$; $(\mathrm{g})$ uma mulher heterossexual solteira que pretende adotar uma rapariga $(n=93)$; (h) uma mulher heterossexual solteira que pretende adotar um rapaz $(n=92)$; (i) um homem heterossexual solteiro que pretende adotar uma rapariga $(n=91)$; (j) um homem heterossexual solteiro que pretende adotar um rapaz $(n=88)$; $(\mathrm{k})$ uma mulher lésbica solteira que pretende adotar uma rapariga $(n=90)$; (1) uma mulher lésbica solteira que pretende adotar um rapaz $(n=91)$; $(\mathrm{m})$ um homem gay solteiro que pretende adotar uma rapariga $(n=88)$; e $(\mathrm{n})$ um homem gay solteiro que pretende adotar um rapaz $(n=91)$. 


\section{Instrumentos}

Questionário sociodemográfico. Para efeitos de caracterização da amostra, recolheu-se informação relativa às variáveis que podem ser observadas na Tabela 1 .

Vinheta. Por se adequar aos objetivos do presente estudo, isto é, avaliar a competência parental de candidatos/as a adotantes em função da sua orientação sexual e estatuto conjugal, foi utilizada uma adaptação da situação-estímulo criada por Camilleri e Ryan (2006), a partir do trabalho de Crawford e Solliday (1996). Trata-se de uma situação de adoção na qual os/as candidatos/as são descritos/as como aptos/as para adotar uma criança de seis anos, variando a sua orientação sexual e estatuto conjugal e também o sexo da criança (uma das versões das 14 vinhetas pode ser consultada no Anexo 1). Esta situação tem a vantagem de uniformizar as condições de partida para exercer um papel parental, independentemente da orientação sexual e estatuto conjugal das pessoas retratadas. No entanto, trata-se de uma descrição necessariamente fictícia, na medida em que não tem em conta os limites estabelecidos pela Lei Portuguesa, nomeadamente no que se refere à impossibilidade de casais do mesmo sexo se apresentarem como candidatos à adoção. Após autorização dos autores, a vinheta original em língua inglesa foi sujeita a um processo de tradução-retroversão para o português. Posteriormente, a validade facial desta versão foi assegurada a partir de uma reflexão falada com um grupo de quatro jovens adultos/as portugueses/as.

Escala de Avaliação das Competências Parentais (adaptado de Crawford, McLeod, Zamboni, \& Jordan, 1999). O instrumento original avalia a perceção que os participantes têm de diversos aspetos da competência parental de um casal candidato à adoção de uma criança. A adaptação do instrumento para a língua portuguesa incluiu um processo de tradução/retroversão e reflexão falada. Dado que no presente estudo se manipulou o estatuto conjugal dos/as candidatos/as a adotantes, foram efetuadas as alterações gramaticais necessárias nos itens (a escala pode ser consultada no Anexo 2).

Selecionaram-se como variáveis dependentes seis itens indicativos dos preconceitos mais comuns relativamente à homoparentalidade (Patterson, 2002). O item 3 diz respeito ao nível de apoio da comunidade aos futuros pais, o item 4 à sua capacidade de transmitir valores, o item 7 à probabilidade de a criança ser vítima de abuso sexual, o item 8 à estabilidade emocional $\mathrm{do} / \mathrm{s}$ candidato/s ou da/s candidata/s a adotante/s, o item 10 à preocupação dos/as participantes com as competências parentais e o item 11 à decisão de atribuição de custódia ao/s candidato/s ou à/s candidata/s em questão. Os/as participantes responderam utilizando uma escala tipo Likert de 1 a 6 , variando as âncoras de resposta consoante o item. Por exemplo, para o item "Em que medida está preocupado/a com as competências parentais deste 
casal/desta pessoa?", os/as participantes exprimiam a sua opinião, desde Nada preocupado/a (1) até Completamente preocupado/a (6).

\section{Procedimento}

Após permissão das respetivas instituições de ensino superior, os questionários foram coletivamente administrados pelo primeiro autor do estudo, no período disponibilizado para o efeito. Antes do preenchimento, os/as participantes foram esclarecidos acerca da natureza voluntária da participação e do propósito genérico do estudo (avaliar atitudes sociais), tendo sido também assegurados o direito à confidencialidade e o anonimato das respostas. Tratando-se de uma manipulação de caráter experimental, o objetivo do estudo só foi divulgado após o preenchimento dos questionários, de forma a não influenciar as respostas dos/as participantes. Neste estudo respeitaram-se os princípios de ação em investigação apresentados no Código Deontológico da Ordem dos Psicólogos Portugueses (OPP, 2011).

\section{Resultados}

Em primeiro lugar, com o objetivo de controlar o possível efeito de algumas variáveis, que poderiam influenciar as respostas dos/as participantes relativamente à homoparentalidade, realizou-se uma análise preliminar na qual se procurou verificar se os/as participantes estavam equitativamente distribuídos nas condições experimentais definidas em função da orientação sexual. Não se observaram diferenças significativas nas frequências de resposta (teste do qui-quadrado), no que diz respeito às seguintes variáveis sociodemográficas: sexo $\left[\chi^{2}(2,1272)=2.05, p=.359\right]$, área curricular $\left[\chi^{2}\right.$ $(6,1272)=4.54, p=.605]$, nível de educação dos pais $\left[\chi^{2}(4,1252)=6.74, p\right.$ $=.150]$, contacto com informação científica relativamente à homossexualidade e à homoparentalidade $\left[\chi^{2}(2,1266)=2.80 p=.247\right]$, contacto interpessoal com lésbicas e gays $\left[\chi^{2}(2,1262)=0.48, p=.785\right]$, e importância atribuída aos valores religiosos $\left[\chi^{2}(4,1263)=9.76, p=.0450\right]$.

Em segundo lugar, para averiguar as tendências de resposta dos/as participantes, comparou-se a média das variáveis dependentes com o ponto médio da escala de Likert (3.5), recorrendo ao teste $t$ de student para uma amostra.

Como se pode observar na Tabela 2, os/as participantes manifestaram, em geral, atitudes globalmente favoráveis, quer à hetero, quer à homoparentalidade. Mais especificamente, os valores médios das respostas aos itens 4 (capacidade de transmitir valores), 8 (estabilidade emocional) e 11 (atribuição de custódia) foram, para todas as orientações sexuais, significativamente superiores ao ponto médio da escala de resposta. No que diz respeito ao item 7 (probabilidade de abuso sexual), observou-se a tendência contrária, isto é, o 
valor médio das respostas foi significativamente inferior a 3.5. As exceções dizem respeito ao item 3 (nível de apoio da comunidade) em que se observaram valores inferiores ao ponto médio da escala de resposta, no caso dos/as adotantes homossexuais (lésbicas e gays) e superiores, no caso dos/as adotantes heterossexuais; e ao item 10 (preocupação com competências parentais), em que se observaram valores significativamente inferiores ao valor 3.5, no caso da homoparentalidade e iguais no caso da heteroparentalidade.

Tabela 2: Comparação Entre as Médias dos Itens e o Ponto Médio da Escala Tipo Likert Utilizada (3.5) Para Cada Orientação Sexual

\begin{tabular}{llllll}
\hline & $M$ & $D P$ & $g l$ & $t$ & $p$ \\
\hline Lésbicas $(n=367)$ & & & & & \\
3.Nível de apoio da comunidade & 3.22 & 1.36 & 366 & -3.91 & $<.001$ \\
4. Capacidade de transmitir valores & 5.02 & 1.13 & 366 & 25.92 & $<.001$ \\
7. Abuso sexual & 1.70 & 0.75 & 366 & $-46.32<.001$ \\
8. Estabilidade emocional do(s) adotante(s) & 4.91 & 1.11 & 366 & 24.40 & $<.001$ \\
10. Preocupação com competências parentais & 2.90 & 1.58 & 366 & -7.27 & $<.001$ \\
11. Atribuição de custódia & 4.66 & 1.33 & 366 & $16.71<.001$
\end{tabular}

Gays $(n=357)$

3.Nível de apoio da comunidade

$\begin{array}{lllll}3.13 & 1.35 & 356 & -5.20 & <.001\end{array}$

4. Capacidade de transmitir valores

$\begin{array}{lllll}5.06 & 1.11 & 356 & 26.42 & <.001\end{array}$

7. Abuso sexual

$\begin{array}{lllll}1.81 & 0.84 & 356 & -37.87<.001\end{array}$

8. Estabilidade emocional do(s) adotante(s)

$\begin{array}{llllll}4.89 & 1.07 & 356 & 24.66 & <.001\end{array}$

10. Preocupação com competências parentais

$\begin{array}{lllll}3.11 & 1.58 & 356 & -4.63 & <.001\end{array}$

11. Atribuição de custódia

$\begin{array}{lllll}4.67 & 1.38 & 356 & 15.98 & <.001\end{array}$

Heterossexuais $(n=538)$

3.Nível de apoio da comunidade

$\begin{array}{lllll}4.18 & 1.45 & 537 & 10.91 & <.001\end{array}$

4. Capacidade de transmitir valores

$\begin{array}{lllll}5.28 & 0.77 & 537 & 53.58 & <.001\end{array}$

7. Abuso sexual

$\begin{array}{llll}1.94 & 0.78 & 537 & -46.14<.001\end{array}$

8. Estabilidade emocional do(s) adotante(s)

$\begin{array}{lllll}4.89 & 0.87 & 537 & 37.08 & <.001\end{array}$

10. Preocupação com competências parentais

$\begin{array}{lllll}3.37 & 1.57 & 537 & -1.89 & .059\end{array}$

11. Atribuição de custódia

$\begin{array}{lllll}5.15 & 0.81 & 537 & 47.51<.001\end{array}$ 
Em terceiro lugar, para verificar o efeito principal da orientação sexual (Lésbica vs. Gay vs. Heterossexual) e da sua interação com o estatuto conjugal (Casais vs. Solteiros/as) sobre as variáveis dependentes, efetuou-se uma Análise Multivariada de Variância (MANOVA). Antes de se realizar esta análise foram removidos 17 casos. $^{5}$ Embora não se verifique a homogeneidade da matriz de variância-covariância (teste de Box significativo), a dimensão da amostra pareceu ser suficiente para garantir a robustez das análises. Além disso, recorreu-se à medida mais conservadora (critério de Pillai) para considerar significativos os efeitos principais ou de interação (Tabachnik \& Fidell, 2001). Sempre que se verificaram efeitos significativos, foram realizadas ANOVAS subsequentes para identificar diferenças nas variáveis dependentes em questão.

Foi detetado um efeito significativo principal da orientação sexual dos candidatos/as a adotantes, [Critério de Pillai $=.19, F(12,2504)=21.35, p<$ $.001, \eta_{p}^{2}=.09$ ] para todos os itens, exceto para o item 8 (estabilidade emocional dos/as adotantes). As análises post-hoc revelaram diferenças significativas em função da orientação sexual (Lésbica vs. Gay vs. Heterossexual), não se tendo verificado diferenças entre as duas primeiras. ${ }^{6}$ Assim, os/as participantes consideraram que, relativamente aos/às candidatos/as homossexuais, os/as candidatos/as heterossexuais teriam maior probabilidade de receber apoio da comunidade, $[F(2,1256)=73.03, M S E=1.93, p<.001$, $\left.\eta_{p}{ }^{2}=.10\right]$ e teriam maior capacidade de transmitir valores, $[F(2,1256)=$ $\left.7.14, M S E=0.97, p=.001, \eta_{p}{ }^{2}=.01\right]$. No entanto, uma criança adotada por heterossexuais teria maior probabilidade de ser abusada sexualmente, do que se fosse adotada por pessoas homossexuais, $[F(2,1256)=11.70, M S E=$ $\left.0.62, p<.001, \eta_{p}{ }^{2}=.02\right]$; os/as participantes manifestaram-se também mais preocupados com as competências parentais dos primeiros do que dos segundos, $\left[F(2,1256)=7.37, M S E=2.48, p=.001, \eta_{p}{ }^{2}=.01\right]$. Não obstante os dois últimos resultados, a probabilidade de atribuição de custódia era maior se a criança fosse adotada por pessoas heterossexuais do que por pessoas homossexuais, $\left[F(2,1256)=27.42, M S E=1.32, p=0.000, \eta_{p}^{2}=.042\right]$ (ver Tabela 3).

${ }^{5}$ Foram identificados, através do cálculo da distância quadrada de Mahalanobis $\left(\mathrm{D}^{2}\right)(p=$ 0.0001 ), em cada uma das condições definidas em função da orientação sexual dos candidatos, um total de 17 outliers multivariados. Uma análise adicional do padrão de respostas dos outliers identificados ditou a eliminação de 16 casos. Para além disso, foi eliminado um caso que não respondeu a nenhum dos itens da escala.

${ }^{6}$ Foi utilizado o teste post-hoc para comparações múltiplas Games-Howell, que não pressupõe a igualdade das variâncias nos diferentes grupos (Field, 2005). 
Tabela 3: Competências Parentais em Função da Orientação Sexual dos Candidatos a Adotantes

\begin{tabular}{lcccc}
\hline & & $\begin{array}{c}\text { Lésbicas } \\
(n=367)\end{array}$ & $\begin{array}{c}\text { Gays } \\
(n=357)\end{array}$ & $\begin{array}{c}\text { Heterossexuais } \\
(n=538)\end{array}$ \\
\hline 3. Nível de apoio da comunidade & $M$ & $3.22^{\mathrm{b}}$ & $3.13^{\mathrm{b}}$ & $4.18^{\mathrm{a}}$ \\
& $(D P)$ & $(1.36)$ & $(1.35)$ & $(1.45)$ \\
4. Capacidade de transmitir valores & $M$ & $5.02^{\mathrm{b}}$ & $5.06^{\mathrm{b}}$ & $5.28^{\mathrm{a}}$ \\
& $(D P)$ & $(1.13)$ & $(1.11)$ & $(0.77)$ \\
7. Abuso sexual & $M$ & $1.70^{\mathrm{b}}$ & $1.81^{\mathrm{b}}$ & $1.94^{\mathrm{a}}$ \\
10. Preocupação com competências & $M$ & $2.90^{\mathrm{b}}$ & $3.11^{\mathrm{b}}$ & $3.37^{\mathrm{a}}$ \\
parentais & $(D P)$ & $(1.58)$ & $(1.58)$ & $(1.57)$ \\
11. Atribuição de custódia & $M$ & $4.66^{\mathrm{b}}$ & $4.67^{\mathrm{b}}$ & $5.15^{\mathrm{a}}$ \\
& $(D P)$ & $(1.33)$ & $(1.38)$ & $(0.81)$ \\
\hline
\end{tabular}

Nota. As médias, na mesma linha, com letras diferentes, são significativamente diferentes entre si.

Embora não se tivesse verificado um efeito principal do estatuto conjugal, a interação da orientação sexual com o estatuto conjugal foi significativa, $\left[\right.$ Critério de Pillai $\left.=.04, F(18,3759)=2.55, p<0.001, \eta_{p}{ }^{2}=.01\right]$ para os itens 3 e 11, referentes respetivamente ao apoio da comunidade, $[F$ (3, $\left.1256)=4.88, M S E=1.93, p=.002, \eta_{p}{ }^{2}=.012\right]$ e à atribuição de custódia, $[F$ $\left.(3,1256)=3.36, M S E=1.32, p=.018, \eta_{p}{ }^{2}=.01\right]$.

Tabela 4: Competências Parentais em Função da Orientação Sexual e do Estatuto Conjugal dos Candidatos a Adotantes

\begin{tabular}{lccccccc}
\hline & & \multicolumn{2}{c}{$\begin{array}{c}\text { Lésbicas } \\
(n=367)\end{array}$} & \multicolumn{2}{c}{$\begin{array}{c}\text { Gays } \\
(n=357)\end{array}$} & \multicolumn{2}{c}{$\begin{array}{c}\text { Heterossexuais } \\
(n=538)\end{array}$} \\
\cline { 2 - 8 } & & $\begin{array}{c}\text { Casais } \\
(n=185)\end{array}$ & $\begin{array}{c}\text { Solteiros } \\
(n=182)\end{array}$ & $\begin{array}{c}\text { Casais } \\
(n=180)\end{array}$ & $\begin{array}{c}\text { Solteiros } \\
(n=177)\end{array}$ & $\begin{array}{c}\text { Casais } \\
(n=187)\end{array}$ & $\begin{array}{c}\text { Solteiros } \\
(n=351)\end{array}$ \\
\hline 3. Nível de apoio da & $M$ & $3.04^{\mathrm{b}}$ & $3.41^{\mathrm{a}}$ & $2.94^{\mathrm{b}}$ & $3.32^{\mathrm{a}}$ & 4.08 & 4.24 \\
comunidade & $(D P)$ & $(1.36)$ & $(1.34)$ & $(1.30)$ & $(1.38)$ & $(1.51)$ & $(1.42)$ \\
11. Atribuição de & $M$ & $4.48^{\mathrm{b}}$ & $4.85^{\mathrm{a}}$ & 4.66 & 4.68 & 5.20 & 5.13 \\
custódia & $(D P)$ & $(1.44)$ & $(1.18)$ & $(1.36)$ & $(1.41)$ & $(0.78)$ & $(0.82)$ \\
\hline
\end{tabular}

Nota. As médias, na mesma linha, com letras diferentes, são significativamente diferentes entre si. 
Como se pode observar na Tabela 4, ANOVAS subsequentes revelaram diferenças significativas entre casais e candidatos/as solteiros/as, apenas nas orientações homossexuais, nos itens respeitantes ao apoio da comunidade e atribuição de custódia. Assim, os/as participantes consideraram que os/as candidatos/as solteiros/as receberiam mais apoio da comunidade do que os casais, quer no caso dos gays, $[F(1,358)=7.36, p=.007]$, quer no caso das lésbicas, $[F(1,366)=6.84, p=.009]$. Apenas no caso das lésbicas os/as participantes atribuíram com maior probabilidade a custódia da criança às candidatas solteiras, do que às candidatas casadas, $[F(1,367)=7.66$, $p=.006]$.

\section{Discussão}

Este estudo analisou as atitudes relativamente à homoparentalidade de um conjunto de futuros intervenientes da rede social. Para tal, procurou-se verificar em que medida variavam as avaliações que os/as participantes faziam da competência parental de candidatos/as a adotantes, em função da sua orientação sexual e do seu estatuto conjugal.

Como esperado, verificou-se que os julgamentos que os/as participantes fazem da competência parental dos/as candidatos/as são influenciados pela orientação sexual e estatuto conjugal dos/as mesmos/as. Mais detalhadamente, os resultados autorizam, pelo menos, duas abordagens interpretativas.

Uma primeira abordagem decorre da análise dos valores médios nas variáveis estudadas. Efetivamente, quando se trata de outcomes positivos (capacidade de transmissão de valores, estabilidade emocional do/s candidato/s e da/s candidata/s, decisão de atribuição de custódia), os valores médios das respostas dos/as participantes situaram-se, para todas as orientações sexuais, do lado positivo da escala de resposta (i.e., médias significativamente superiores ao ponto médio da escala tipo Likert utilizada). No que diz respeito ao outcome mais negativo, isto é, a probabilidade de a criança ser abusada sexualmente, sucedeu o oposto (i.e., médias significativamente inferiores a 3.5). As diferenças entre as atitudes relativamente à homo versus heteroparentalidade relacionaram-se com a perceção do nível de apoio da comunidade, tendo os/as participantes avaliado positivamente os/as candidatos/as heterossexuais e negativamente as lésbicas e os gays.

Esta avaliação, globalmente positiva, nomeadamente no que diz respeito à decisão de atribuição de custódia, não reflete a opinião da população geral portuguesa face à adoção por casais do mesmo sexo (Comissão Europeia, 2007). No entanto, a idade dos/as participantes (jovens adultos/as), a sua elevada formação académica e o seu sexo (maioritariamente mulheres), poderão explicar parcialmente tais resultados (Gato \& Fontaine, 2011c). 
Uma segunda abordagem interpretativa parece particularmente útil para enquadrar o efeito significativo da orientação sexual dos/as candidatos/as na avaliação da sua competência parental. A homoparentalidade foi avaliada mais positivamente do que a heteroparentalidade em dois casos, sucedendo o inverso em três outros. Por um lado, os/as respondentes percecionaram que uma criança teria maior probabilidade de ser abusada sexualmente se fosse adotada por pessoas heterossexuais, o que poderá refletir uma perceção fidedigna da realidade, sabendo-se que, de facto, as situações de abuso sexual são geralmente perpetradas em contexto heteroparental (Maria \& Ornelas, 2010). Os/as participantes manifestaram também maior preocupação com as competências parentais das pessoas heterossexuais, do que com as das lésbicas e dos gays. Este resultado poderá indiciar a consciência de que, por enfrentarem mais obstáculos do que as famílias heteroparentais para ter filhos, as lésbicas e os gays estarão mais motivados/as para a parentalidade, investindo mais na mesma. Por outro lado, os/as participantes consideraram que os/as candidatos/as heterossexuais receberiam mais apoio da comunidade do que os/as candidatos/as homossexuais e teriam maior capacidade de transmitir valores, atribuindo com maior probabilidade a custódia aos/às primeiros/as do que aos/às segundos/as. O facto de os/as participantes terem percecionado que as famílias homoparentais beneficiariam de menos apoio social não indica, por si só, a existência de preconceito, podendo refletir, simplesmente, a consciência dos índices de preconceito que ainda se verificam na sociedade portuguesa (Gato \& Fontaine, 2011c). Já no que diz respeito à diferença na capacidade de transmitir valores, esta indicia uma apreciação mais preconceituosa das pessoas com orientação sexual gay e lésbica (Patterson, 2002), que se refletiria assim na sua capacidade parental, uma vez a custódia é atribuída com maior probabilidade a pessoas heterossexuais; isto, apesar de os/as candidatos/as heterossexuais serem avaliados/as menos positivamente em duas outras variáveis - abuso sexual e preocupação com as competências parentais. Maximiza-se assim a discriminação, acrescentando uma outra, baseada na maior probabilidade da pessoa ser discriminada, fenómeno que configura uma culpabilização da vítima ou "blame the victim" (Ryan, 1971, in Waller, 2001). Esta atitude é também protetora da identidade dos/as futuros/as profissionais da rede social, que se quer não preconceituosa: os/as candidatos/as não heterossexuais não são genericamente vistos/as como incompetentes, residindo o problema numa sociedade que ainda discrimina, facto que poderá ter sido decisivo na atribuição de custódia. Em suma, embora a homoparentalidade não seja vista negativamente, a custódia da criança é atribuída com maior probabilidade às famílias heteroparentais, resultado consistente com os encontrados em estudos anteriores, quer no que diz respeito ao maior favorecimento da parentalidade heterossexual, quer no que se refere à não identificação de diferenças, em termos de 
efeito principal, entre a homoparentalidade feminina e masculina (Camilleri \& Ryan, 2006; Crawford et al., 1999; Fraser et al., 1995).

A apreensão relativamente às situações de monoparentalidade (DePaulo \& Morris, 2005; Morris, Sinclair, \& DePaulo, 2007; Usdanksy, 2009) não encontrou eco neste estudo uma vez que não se verificaram diferenças significativas entre candidatos/as celibatários/as e casados/as, na maior parte das variáveis estudadas. No entanto, verificou-se uma interação significativa entre a orientação sexual e o estatuto conjugal, na antecipação do nível de apoio da comunidade e na decisão de atribuição de custódia. Assim, os/as participantes consideraram que as lésbicas ou os gays celibatários receberiam mais apoio da comunidade do que os casais do mesmo sexo (femininos ou masculinos). Sem afastar a possibilidade de este resultado estar associado à perceção de uma maior necessidade de apoio social por parte das famílias monoparentais, o facto de tal se verificar apenas no caso das lésbicas e dos gays poderá refletir também a apreensão no que diz respeito à adoção por casais do mesmo sexo (Comissão Europeia, 2007), que seriam assim mais discriminados e menos apoiados pela comunidade. No caso das lésbicas, verificou-se ainda uma maior probabilidade de atribuição da custódia da criança a uma pessoa solteira do que a um casal. Diversas hipóteses concorrentes surgem para explicar este resultado. Primeiro, as lésbicas casadas poderão ter sido desfavorecidas relativamente às suas congéneres celibatárias por veicularem, de forma visível, a mensagem de que um homem não é imprescindível para exercer a parentalidade. Nesta medida, as lésbicas casadas representariam uma maior ameaça a uma sociedade patriarcal, dominada pelos homens. Este tipo de discriminação configuraria o que se designa por "lesbofobia", preconceito que "recrimina os sujeitos percecionados como lésbicos por, ao não cumprirem a compulsão heterossexual natural e não estarem ao dispor sexual dos sujeitos masculinos, não serem verdadeiras mulheres, estatuto que só merecem os sujeitos femininos heterossexuais e/ou maternais, e domésticos" (Rocha, 2010, p. 10). Segundo, este resultado poderá estar associado a uma perceção de maior controlabilidade da orientação sexual no caso das lésbicas, do que no caso dos gays. Não estando dispostas a "controlar" a sua orientação, pelo menos de uma forma socialmente mais visível do que as suas congéneres celibatárias, as lésbicas casadas seriam, por isso, mais sancionadas. Neste sentido, no estudo de Crawford e colaboradores (1999), os/as participantes expressavam maior preocupação com a adoção por um casal lésbico, do que por um casal gay ou heterossexual, quando eram da opinião que a orientação sexual era uma questão de escolha. Terceiro, tendo em conta que a amostra é maioritariamente feminina, os resultados podem ser interpretados como uma resposta a uma perceção de ameaça a dois aspetos presumivelmente nucleares da identidade social das participantes, isto é, a conjugalidade e a maternidade (Tajfel \& 
Turner, 1986). Por outras palavras, podemos estar perante um mecanismo de proteção da identidade heterossexual feminina através da derrogação daquelas que não a aceitam de forma visível e pública, isto é, as lésbicas casadas.

Globalmente, os resultados apresentados permitem observar uma avaliação mais negativa da homoparentalidade do que da heteroparentalidade. Se tal se verificou numa situação em que os/as candidatos/as reúnem as condições ideais para a parentalidade, perante realidades familiares necessariamente imperfeitas é possível que estes preconceitos possam vir a assumir um papel mais proeminente.

Os resultados desta investigação devem, no entanto, ser lidos com alguma cautela. Desde logo, porque a pequena magnitude dos efeitos impõe os necessários limites à generalização dos resultados para a situação natural. De salientar ainda que as avaliações feitas neste estudo se podem generalizar mais às famílias homoparentais adotivas do que a outras configurações homoparentais. Provavelmente, situações de homoparentalidade na sequência de maternidade de substituição ou de inseminação/procriação medicamente assistida suscitariam diferentes atitudes. Finalmente, mesmo a utilização de um desenho semiexperimental, no qual os/as participantes foram confrontados/as apenas com uma situação, pode não ter impedido a manifestação da desejabilidade social.

Dado que a homoparentalidade diz respeito não só aos pais e às mães, mas também à criança, estudos futuros deverão incluir, além de uma avaliação da competência parental, uma medida de antecipação do desenvolvimento da criança. Adicionalmente, as atitudes relativamente à homoparentalidade poderão ser relacionadas com outras variáveis, cujo impacto será tido em conta em estudos futuros, tais como o sexo dos/as participantes, o contacto interpessoal com lésbicas e gays, as atitudes face a lésbicas e a gays ou a adesão a papéis de género tradicionais. O impacto da variável independente sexo da criança poderá também ser verificado em investigações subsequentes.

Não obstante as limitações apontadas, do presente trabalho decorrem algumas implicações. Dada a complexidade de temáticas que afetam a vida das famílias homoparentais (e. g., consequências de se pertencer a um grupo estigmatizado, falta de reconhecimento legal, receio de que os direitos parentais sejam usurpados, entre outras), o conhecimento dos desafios e especificidades desta configuração familiar é um elemento essencial para conhecer e lidar eficazmente com as necessidades de mães lésbicas, pais gays e seus filhos. Moleiro e Pinto (2009) salientam, no âmbito da Psicologia, "a urgente necessidade [em Portugal] da introdução das temáticas LGBT nos curricula académicos das formações graduadas e pós-graduadas" (p. 170). Também Oliveira, Pereira, Costa e Nogueira (2010) propõem, "a criação de currículos onde a orientação sexual e a identidade de género sejam discutidas de forma não preconceituosa - em todos os níveis escolares e académicos” (p. 210). 
Os resultados do presente estudo chamam sobretudo a atenção para as atitudes dos/as futuros/as profissionais da rede social e para a necessidade da abordagem desta temática em diversas áreas de formação, em particular naquelas que preparam pessoas que possam vir a trabalhar diretamente com famílias homoparentais, como é o caso da amostra selecionada. Neste sentido, várias associações profissionais americanas já se pronunciaram e emitiram diretrizes de caráter ético para os seus membros, no que diz respeito à defesa dos direitos e não discriminação das famílias homoparentais. Destacam-se, nomeadamente, as tomadas de posição de médicos, psicólogos, psicanalistas, juristas ou assistentes sociais (APA, 2005).

Finalmente, uma abordagem, originalmente no domínio da psicoterapia, que se mostrou útil para ajudar as pessoas LGB a lidar com a discriminação de que são objeto, é o chamado Modelo Afirmativo Gay (Carneiro, 2009; Davies \& Neal, 2000). Este consiste num conjunto de princípios que orientam a intervenção psicológica junto de pessoas LGB, redirecionando o foco de atenção da pessoa e, acrescentamos nós, da família homoparental, para o contexto homofóbico em que se inserem. Carneiro (2009) salienta a importância desta abordagem se estender a outros domínios da Psicologia que não apenas o da psicoterapia, propondo que se fale antes de uma Psicologia Afirmativa Gay. Permitimo-nos ir um pouco mais longe, sublinhando a necessidade de alargar o compromisso com estes propósitos afirmativos a todos os cursos que preparam pessoas para lidar com pessoas. Seria, assim, mais adequado falar de uma Intervenção Social Afirmativa Gay. Criar uma sociedade mais justa e inclusiva, com implicações para o bem-estar das famílias homoparentais, é um desafio que se coloca a todos/as os/as intervenientes da rede social.

\section{Referências}

Alarcão, M. (2000). Desequilibrios familiares: Uma visão sistémica. Coimbra: Quarteto.

Almeida, M. V. (2009). A chave do armário: Homossexualidade, casamento, família. Lisboa: ICS.

APA - American Psychological Association (2005). Lesbian and Gay Parenting. Retirado de http://www.apa.org/pi/lgbt/resources/parenting-full.pdf

Biblarz, T. J., \& Stacey, J. (2010). How does the gender of parents matter?. Journal of Marriage and Family, 72, 3-22.

Bos, H. M., van Balen, F., van den Boom, D., \& Sandfort, T. G. (2004). Minority stress, experience of parenthood and child adjustment in lesbian families. Journal of Reproductive and Infant Psychology, 22(4), 291-304.

Boyer, C. A. (2007). Double Stigma: The impact of adoption issues on lesbian and gay adoptive parents. In R. A. Javier, A. L. Baden, F. A. Biafora, \& A. 
Camacho-Gingerich (Eds.), Handbook of Adoption: Implications for researchers, practitioners, and families (pp. 228-241). California: Sage Publications.

Camilleri, P., \& Ryan, M. (2006). Social work students' attitudes toward homosexuality and their knowledge and attitudes toward homosexual parenting as an alternative family unit: An Australian study. Social Work Education, 25 (3), 288-304 .

Carneiro, N. S. (2009). Homossexualidades: Uma Psicologia entre o ser, pertencer e participar. Porto: Livpsic.

Clarke, V. (2000). Stereotypes, attack and stigmatize those who disagree: Employing scientific rhetoric in debates about lesbian and gay parenting. Feminism and Psychology, 10(1), 152-159.

Comissão Europeia (2007). Special Eurobarometer 263. Discrimination in the European Union EU25. Retirado de http://ec.europa.eu/public_opinion/ archives/ebs/ebs_263_su_en.pdf

Crawford, I., McLeod, A., Zamboni, B., \& Jordan, M. (1999). Psychologists' attitudes toward gay and lesbian parenting. Professional Psychology: Research and Practice, 30(4), 394-401.

Crawford, I., \& Solliday, E. (1996). The attitudes of undergraduate college students toward gay parenting. Journal of Homosexuality, 30(4), 63-77.

Davies, D., \& Neal, C. (Eds.) (2000). Therapeutic perspectives on working with lesbian, gay and bisexual clients. Buckingham: Open University Press.

DePaulo, B. M., \& Morris, W. L. (2005). Singles in society and in science. Psychological Inquiry, 16, (2/3), 57-83.

Diário da República (2001). I Série-A. N. ${ }^{\circ}$ 109, 11 de maio, 2797-2798.

Diário da República (2003). I Série-A. N. ${ }^{\circ}$ 193, 22 de agosto, 5313-5314.

Diário da República (2010). I Série, N. ${ }^{\circ} 105,31$ de maio, 1853.

Ferreira, E. (2006). Actas do Encontro sobre Homoparentalidade. Lisboa: ISPA Edições.

Field, A. (2005). Discovering statistics using SPSS ( $2^{\text {nd }}$ Ed). London: Sage.

Fraser, I., Fish, T., \& Mackenzie, T. (1995). Reactions to child custody decisions involving homosexual and heterosexual parents. Canadian Journal of Behavioural Science, 27(1), 52-63.

Gato, J., \& Fontaine, A. M. (2011a). Impacto da orientação sexual e do género na parentalidade: Uma revisão dos estudos empíricos com famílias homoparentais. Revista Ex-Aequo, 23, 83-89.

Gato, J., \& Fontaine, A. M. (2011b). Desconstruindo preconceitos sobre a homoparentalidade. LES Online, 2(2). Retirado de http://www.lespt.org/lesonline/ index.php?journal=lo\&page $=$ article \&op $=$ view $\&$ path $\% 5 \mathrm{~B} \% 5 \mathrm{D}=34$

Gato, J., \& Fontaine, A. M. (2011c). Factores associados ao preconceito homossexual numa amostra de estudantes universitários portugueses: A influência do sexo, do contacto interpessoal com lésbicas e gays, dos valores sociais e das atitudes de género. In S. Neves (Coord.), Género e ciências sociais (pp. 155-172). Castêlo da Maia: Edições ISMAI.

Herek, G. M. (1988). Heterosexuals' attitudes toward lesbians and gay men: Correlates and gender differences. The Journal of Sex Research, 25(4), 451-477. 
King, B., \& Black, K. (1999). College students' perceptual stigmatization of the children of lesbian mothers. American Journal of Orthopsychiatry, 69(2), 220$-227$.

Kite, M. E., \& Whitley, B. E. (1998). Do heterosexual women and men differ in their attitudes toward homosexuality? A conceptual and methodological analysis. In G. M. Herek (Ed.), Psychological Perspectives on Lesbian and Gay Issues. Stigma and Sexual Orientation, Understanding Prejudice Against Lesbians, Gay Men, and Bisexuals, Vol. 4 (pp. 39-61). Thousand Oaks, CA: Sage.

LaMar, L., \& Kite, M. (1998). Sex differences in attitudes toward gay men and lesbians: A multidimensional perspective. The Journal of Sex Research, 35(2), 189-196.

Leal, I. (2004). Parentalidades. Questões de género e orientação sexual. In A. F. Cascais (Org.), Indisciplinar a teoria: Estudos Gays, Lésbicos e Queer (pp. 215-243). Lisboa: Fenda.

Maria, S., \& Ornelas, J. (2010). O papel da comunidade na prevenção dos abusos sexuais de crianças (ASC). Análise Psicológica, 28(3), 411-436.

McLeod, A., Crawford, I., \& Zechmeister, J. (1999). Heterosexual undergraduates' attitudes toward gay fathers and their children. Journal of Psychology and Human Sexuality, 11(1), 43-62.

Moita, G. (2006). A patologia da diversidade sexual: Homofobia no discurso de clínicos. Revista Crítica das Ciências Sociais, 76, 53-72.

Moleiro, C., \& Pinto, N. (2009). Diversidade e psicoterapia: Expectativas e experiências de pessoas LGBT acerca das competências multiculturais de psicoterapeutas. Revista Ex-Aequo, 20, 159-172.

Morris, W. L., Sinclair, S., \& DePaulo, B. M. (2007). No shelter for singles: The perceived legitimacy of marital status discrimination. Group Process \& Intergroup Relations, 10(4), 457-470.

Moz, M. (2006). Diferenças de género e famílias homoparentais. Actas do III Congresso da Associação Portuguesa de Antropologia. Retirado de http:/www.apantropologia.net/publicacoes/actascongresso2006/cap6/MozMar garida.pdf

Oliveira, J. M., Pereira, M., Costa, C.G., \& Nogueira, C. (2010). Pessoas LGBT Identidades e discriminação. In C. Nogueira \& J. M. Oliveira (Orgs.), Estudo sobre a discriminação em função da orientação sexual e da identidade de género (pp. 149-210). Lisboa: Comissão para a Cidadania e a Igualdade de Género.

OPP - Ordem dos Psicólogos Portugueses (2011). Regulamento n. ${ }^{\circ}$ 258/2011. Diário da República ${ }^{\circ} 78$, Série II de 20 de abril de 2011.

Pakizegi, B. (2007). Single-Parent Adoptions and Clinical Implications. In R. A. Javier, A. L. Baden, F. A. Biafora \& A. Camacho-Gingerich (Eds.), Handbook of Adoption: implications for researchers, practitioners, and families (pp. 190-216). California: Sage Publications.

Patterson, C. J. (2002). Lesbian and gay parenthood. In M. H. Bornstein (Ed.), Handbook of Parenting, Vol. 3: Being and Becoming a Parent (pp. 317-338). New Jersey: Lawrence Erlbaum Associates. 
Rocha, A. (2010). To the 80's and back: Que visibilidade lésbica afinal? LES Online, 2(1). Retirado de http://www.lespt.org/lesonline/index.php?journal=lo\&page $=$ article\&op $=$ view $\&$ path $\% 5 \mathrm{~B} \% 5 \mathrm{D}=24$

Stacey, J., \& Biblarz, T. J. (2001). (How) does the sexual orientation of parents matter?. American Sociological Review, 66, 159-183.

Tabachnik, B., \& Fidell, L. (2001). Using multivariate statistics (4 ${ }^{\text {th }}$ Ed). Boston: Allyn and Bacon.

Tajfel, H., \& Turner, J. C. (1986). The social identity theory of intergroup behaviour. In S. Worchel \& W.G. Austin (Eds.), Psychology of intergroup relations (pp. 7-24) (2 $2^{\text {th }}$ Ed). Chicago: Nelson-Hall.

Tasker, F. (2005). Lesbian mothers, gay fathers, and their children: A review. Journal of Developmental \& Behavioral Pediatrics, 26(3), 224-240.

Usdanksy, M. L. (2009). A weak embrace: Popular and scholarly depictions of single-parent families, 1900 - 1998. Journal of Marriage and Family, 71, 209-225 .

Vecho, O., \& Schneider, B. (2005). Homoparentalité et développement de l'enfant: Bilan de trente ans de publications. La Psychiatrie de l'Enfant, 481, 271-328.

Waller, M. A. (2001). Resilience in ecosystemic context: Evolution of concept. American Journal of Orthopsychiatry, 71(3), 1-8.

Whitley, B.E. (1988). Sex differences in heterosexuals' attitudes toward homosexuals: It depends upon what you ask. The Journal of Sex Research, 24, 287-291.

\section{Anexo 1. Exemplo de uma Vinheta}

A Catarina tem 35 anos, é solteira e homossexual. Não tem filhos e decidiu adotar. Tem habilitações de nível superior (é arquiteta) e é bem sucedida profissionalmente. É estimada pelos seus vizinhos e amigos e, na sua história pessoal, não há referência a doenças psiquiátricas, abuso de substâncias, dificuldades financeiras ou problemas legais. É proprietária de uma casa com três quartos no Porto e sente-se financeira e emocionalmente preparada para educar uma criança. Além do mais, tanto o seu pai como a sua mãe estão entusiasmados com esta ideia e dispostos a prestar todo o apoio necessário.

A Catarina conheceu o Rui, um rapaz português de seis anos, cujos pais faleceram num acidente rodoviário, quando ele tinha dois anos. Esta criança está a viver numa instituição de acolhimento, sob a responsabilidade da Segurança Social. A Catarina tem visitado regularmente o Rui durante os últimos doze meses e os dois concordam que se têm dado muito bem. O Rui afirmou que gostaria de ir viver com a Catarina. Esta, após considerar cautelosamente todas as implicações desta decisão, sente que pode oferecer ao Rui um lar acolhedor e avançou com o processo de adoção formal. 


\section{Anexo 2. Escala de Avaliação das Competências Parentais (adap- tado de Crawford, McLeod, Zamboni, \& Jordan, 1999)}

Com base na história que acabou de ler, posicione-se quanto às seguintes questões:

1. Em que medida considera que a adoção é a melhor alternativa para uma criança órfã de 6 anos, que esteja sob a custódia do Estado?

2. Em que medida está preocupado/a com a estabilidade financeira da pessoa [do casal] que pretende adotar a criança?

3. Qual o nível de apoio que considera que esta pessoa [este casal] receberia da sua comunidade, ao criar esta criança?

4. Como avalia a capacidade desta pessoa [deste casal] transmitir valores e criar uma criança moralmente responsável?

5. Na sua opinião, qual a probabilidade desta criança vir a ser vítima de negligência emocional?

6. Na sua opinião, qual a probabilidade desta criança vir a ser vítima de violência física?

7. Na sua opinião, qual a probabilidade desta criança vir a ser vítima de abuso sexual?

8. Como avalia a estabilidade emocional da pessoa [das pessoas] que preten$\mathrm{de}[\mathrm{m}]$ adotar esta criança?

9. Que expectativa tem acerca da estabilidade desta pessoa [deste casal] no futuro?

10. Em que medida está preocupado/a com as competências parentais desta pessoa [deste casal]?

11. Se fosse você a decidir, qual a probabilidade de atribuir a custódia desta criança a esta pessoa [casal]? 